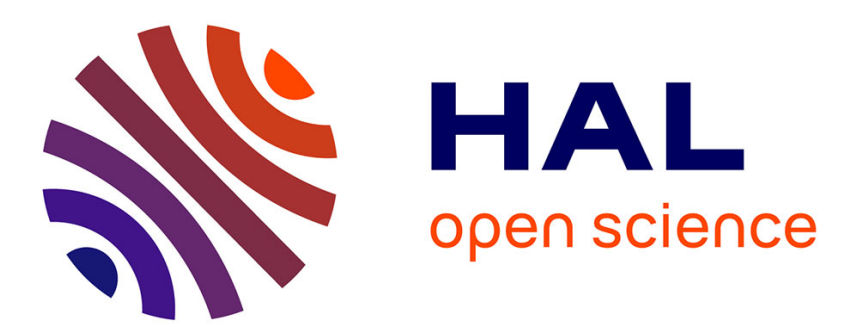

\title{
Design and characterization of an efficient dual patch rectenna for Microwave Energy Recycling in the ISM Band
}

Hakim Takhedmit, Laurent Cirio, Odile Picon, Christian Vollaire, Bruno Allard, François Costa

\section{To cite this version:}

Hakim Takhedmit, Laurent Cirio, Odile Picon, Christian Vollaire, Bruno Allard, et al.. Design and characterization of an efficient dual patch rectenna for Microwave Energy Recycling in the ISM Band. Progress In Electromagnetics Research C, 2013, 43, pp.93-108. 10.2528/PIERC13073105. hal03122577

\section{HAL Id: hal-03122577 \\ https://hal.science/hal-03122577}

Submitted on 27 Jan 2021

HAL is a multi-disciplinary open access archive for the deposit and dissemination of scientific research documents, whether they are published or not. The documents may come from teaching and research institutions in France or abroad, or from public or private research centers.
L'archive ouverte pluridisciplinaire HAL, est destinée au dépôt et à la diffusion de documents scientifiques de niveau recherche, publiés ou non, émanant des établissements d'enseignement et de recherche français ou étrangers, des laboratoires publics ou privés. 
DESIGN AND CHARACTERIZATION OF AN EFFICIENT DUAL PATCH RECTENNA FOR MICROWAVE ENERGY RECYCLING IN THE ISM BAND

\author{
Hakim Takhedmit ${ }^{1,}{ }^{*}$, Laurent Cirio ${ }^{1}$, Odile Picon ${ }^{1}$, \\ Christian Vollaire ${ }^{2}$, Bruno Allard ${ }^{2}$, and François Costa ${ }^{3}$ \\ ${ }^{1}$ ESYCOM Laboratory, Université Paris-Est, EA2552, UPEMLV, \\ Champs-sur-Marne 77454, France \\ 2AMPERE Laboratory, UMR 5005, EC-INSA Lyon, Lyon 69130, \\ France
}

${ }^{3}$ SATIE Laboratory, UMR 8029, ENS Cachan, Cachan 94235, France

\begin{abstract}
This paper describes the design, modeling and optimization of an efficient ISM band dual patch rectenna capable of achieving more than $80 \%$ RF-to-DC conversion efficiency at low/medium power densities. The circuit is based on a full-wave rectifier, designed and optimized at $2.45 \mathrm{GHz}$ with ADS software and the FDTD algorithm. The performances of the rectenna have been accurately predicted using the full-wave 3D-FDTD method extended to lumped linear and non-linear elements. It exhibits $73 \%\left(V_{\mathrm{DC}}=1.1 \mathrm{~V}\right.$ for $\left.R_{L}=1.2 \mathrm{k} \Omega\right)$ measured efficiency at a low power density of $14 \mu \mathrm{W} / \mathrm{cm}^{2}$ and $84 \%\left(V_{\mathrm{DC}}=1.94 \mathrm{~V}\right)$ at $43 \mu \mathrm{W} / \mathrm{cm}^{2}$. The differences between the experimental and FDTD simulated efficiencies are less than $3 \%$. The proposed circuit is particularly suitable for low/medium power recycling and power remote supply of wireless sensors, sensor nodes and actuators.
\end{abstract}

\title{
1. INTRODUCTION
}

The growing proliferation of wireless communication devices raises the issue of their energy autonomy. The remote and contactless powering of abandoned sensors and actuators is a sample of application. Conventional solutions like the use of batteries present constraints of lifetime and recycling operations. The concept of wireless power transmission (WPT) [1] using far-field RF radiation appears as an

\footnotetext{
Received 31 July 2013, Accepted 17 September 2013, Scheduled 18 September 2013
}

* Corresponding author: Hakim Takhedmit (Hakim.Takhedmit@univ-mlv.fr). 
attractive alternative. In this study, we focused on the microwave capture and conversion in the ISM (Industrial-Scientific-Medical) band at $2.45 \mathrm{GHz}$.

The key component of a WPT system is called rectenna $[2,3]$. It contains a receiving antenna and an RF-to-DC rectifier. The rectifier is often made up of a combination of Schottky diodes, an input HF filter, an output bypass capacitor and an output load resistor that models the input impedance of the device to be powered. The output dc filter is often constituted by a lumped shunt capacitor [2,4-7], a distributed microstrip low-pass filter [3] or a radial stub $[8,9]$. In addition, via-hole connections are often used for dc path [3-8].

The RF-to-DC rectifier can take several configurations. The single serial $[3,4,8]$ and shunt $[2,5]$ configurations are the most used. The voltage doubler $[2,6,7]$ topology can also be used so as to enhance the output dc voltage. To achieve high dc output (power and/or voltage), antenna arrays $[10-12]$ or rectenna arrays $[2,12-14]$ have to be used to rectify a large amount of incoming power. In rectenna arrays, different interconnection topologies of elements can be considered: series, parallel and cascaded. For a given input RF power level, the RF-to-DC conversion efficiency is mainly affected by the diode losses, which are dominant, and the impedance mismatching. In addition, the receiving antenna efficiency affects greatly the global efficiency of the rectenna.

In [15], the authors propose an ISM band rectenna operating at $2.45 \mathrm{GHz}$. It consists of a modified circular monopole loaded with a rectangular ring and a half-wave rectifier. It exhibits a maximum efficiency of $50 \%$ at $155 \mu \mathrm{W} / \mathrm{cm}^{2}$.

A rectenna for $\mathrm{RF}$ energy scavenging at $866 \mathrm{MHz}$ is reported in [16]. It uses a modified bowtie antenna to collect the electromagnetic energy coming from UHF RFID systems, and Schottky diodes for the RF-to-DC conversion. An experimental efficiency of about $65 \%$ is obtained at $60 \mu \mathrm{W} / \mathrm{cm}^{2}$.

A dual-band rectenna, operating at 1.96 and $2.45 \mathrm{GHz}$, is described in [17] and dedicated for wireless powering at low power densities, from 20 to $200 \mu \mathrm{W} / \mathrm{cm}^{2}$. Measured efficiencies of about 54 and $57 \%$ were obtained in the two frequency bands, respectively.

This paper addresses design, optimization and characterization of a high-efficiency ISM band dual patch rectenna well suitable for driving smart actuators [13] and wireless sensors or sensor nodes [18]. Then, the circuit has been optimized to operate at $10 \mathrm{~mW}$ RF input power which corresponds to a power density of about $100 \mu \mathrm{W} / \mathrm{cm}^{2}$ on the dual patch antenna and an efficiency of $87 \%$ but some results will be also given at low power (around $1 \mathrm{~mW}$ ). Unlike the most published 
results on the RF-to-DC rectifying circuit, the proposed structure needs neither via-hole connections nor bypass capacitor. This is due to its symmetrical topology. Further, no input HF filter has been used resulting in a simpler structure.

This paper is organized as follows: a description of the dual accesses microwave rectifier is given in Section 2, followed by an accurate 3D-FDTD modeling of the rectenna in Section 3 . Experimental characterization, results and comments are given in Section 4.

\section{MICROWAVE RECTIFIER: DESIGN AND OPTIMIZATION}

The RF-to-DC rectifier shown in Fig. 1 is based on a symmetrical bridge with two microstrip accesses. It has been designed and optimized at $2.45 \mathrm{GHz}$ and $10 \mathrm{~mW}$ RF input power $(5 \mathrm{~mW}$ on each access). The parameters such as microstrip-line lengths, characteristic impedances and resistive load have been optimized using Advanced Design System (ADS) [19]. To take into account all the electromagnetic couplings between elements, a global analysis technique [9] that associates Momentum electromagnetic simulator and Harmonic Balance (HB), has been achieved.

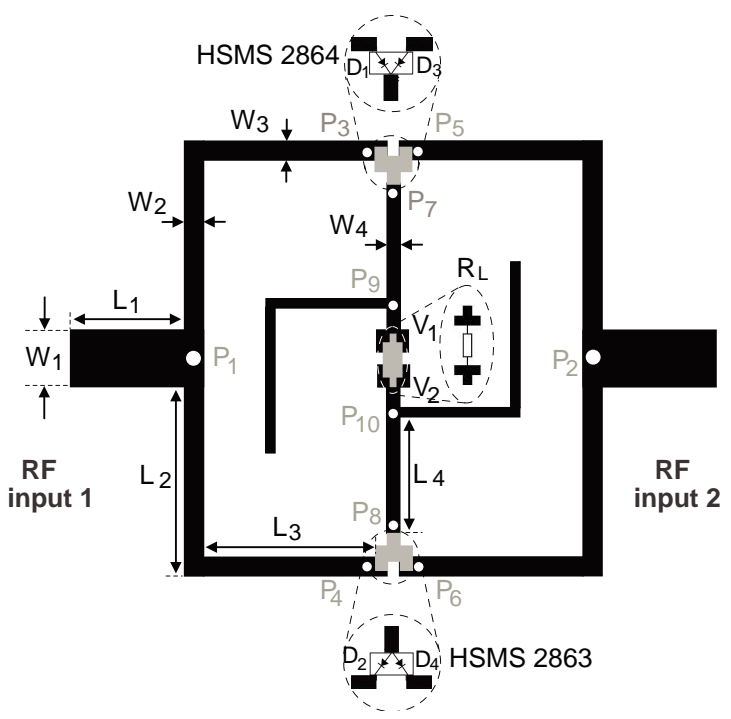

Figure 1. Layout of the full-wave rectifier. 
The rectifier was etched on Rogers Duroid 5880 substrate $\left(\varepsilon_{r}=\right.$ $2.2, h=1.575 \mathrm{~mm}$ and $\tan \delta=0.0009$ ), it includes four Schottky diodes $\left(D_{1}\right.$ to $\left.D_{4}\right)$. Diodes are arranged by pair and mounted on single surface mount SOT 23 packages, one with common anode (HSMS-2863) and the second with common cathode (HSMS-2864), and operate from $915 \mathrm{MHz}$ to $5.8 \mathrm{GHz}$. These diodes are characterized by a forward and breakdown voltages of 0.3 and $7 \mathrm{~V}$, respectively. The zero bias junction capacitance $C_{j 0}$ is $0.18 \mathrm{pF}$ and the series resistance $R_{s}$ is $5 \Omega$ [20]. Two folded quarter wavelength open stubs, connected at points $P_{9}$ and $P_{10}$, behave like short circuits at the operating frequency and therefore isolate the resistive load $R_{L}$. At the point $P_{1}\left(P_{2}\right)$, the incident $\mathrm{RF}$ power from access 1 (2) is split in two balanced RF components which propagate in phase towards diodes $D_{1}$ and $D_{2}\left(D_{3}\right.$ and $\left.D_{4}\right)$. Due to the non-linear characteristic of diodes, the incident RF signal is then partially converted into dc current. Moreover, high-order harmonics components are generated.

The output dc voltage $\left(V_{\mathrm{DC}}=V_{1}-V_{2}\right)$ is measured across an output resistive load of $1.2 \mathrm{k} \Omega$ without reference to the ground plane, optimized at $10 \mathrm{~mW}$ received power. Thus, there is no need of via-hole connections. The optimization criterion is based on the RF-to-DC conversion efficiency $(\eta)$, defined as follows:

$$
\eta(\%)=100 \times \frac{P_{\mathrm{DC}}}{P_{\mathrm{RF}}}=100 \times \frac{V_{\mathrm{DC}}^{2}}{P_{\mathrm{RF}} \times R_{L}}
$$

where $P_{\mathrm{RF}}$ is the total RF input power on both accesses (1 and 2), $P_{\mathrm{DC}}$ the output dc power, and $V_{\mathrm{DC}}$ the output voltage over the resistive load $\left(R_{L}\right)$.

Table 1 summarizes the optimized dimensions and the characteristic impedances of microstrip-line sections of the rectifier. These parameters, and the output load value, are accurately adjusted so as to maximize the RF-to-DC conversion efficiency and considering a simulated serial diode impedance of $78-j 256 \Omega$ at $10 \mathrm{~mW}$ RF input power.

Table 1. Lengths, widths and characteristic impedances of the line sections.

\begin{tabular}{|c|c|c|c|}
\hline Microstrip-line section & Length $(\mathrm{mm})$ & Width $(\mathrm{mm})$ & $Z_{C}(\Omega)$ \\
\hline$L_{1}, W_{1}$ & 10 & 4.8 & 50 \\
\hline$L_{2}, W_{2}$ & 17.6 & 1.53 & 95 \\
\hline$L_{3}, W_{3}$ & 17.9 & 1.53 & 95 \\
\hline$L_{4}, W_{4}$ & 11.5 & 0.95 & 117 \\
\hline
\end{tabular}




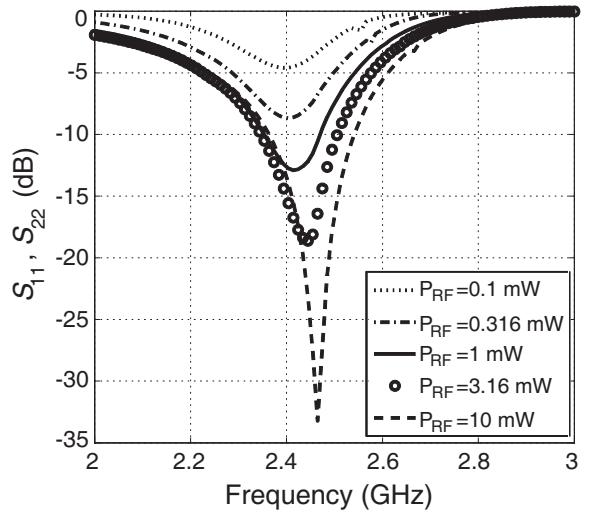

(a)

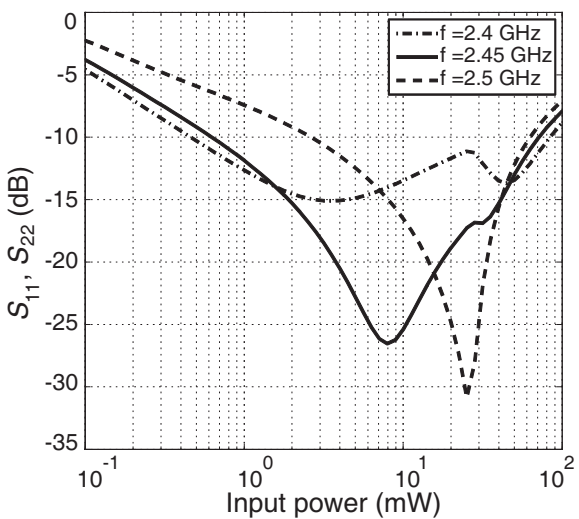

(b)

Figure 2. Input reflection coefficient versus: (a) RF frequency, (b) input RF power.

The simulated reflection coefficient $\left(S_{11}, S_{22}\right)$ of the rectifier versus frequency is depicted in Fig. 2(a). Simulations are made considering five RF power levels: 0.1, 0.316, 1, 3.16 and $10 \mathrm{~mW}$. The results clearly show that the rectifier is correctly matched around $2.45 \mathrm{GHz}$ and $10 \mathrm{~mW}$ RF power level. Fig. 3(b) shows the simulated reflection coefficient $\left(S_{11}, S_{22}\right)$ of the rectifier when the input RF power varies from 0.1 up to $100 \mathrm{~mW}$. Results are depicted at 2.4, 2.45 and $2.5 \mathrm{GHz}$. Due to the nonlinear characteristic of the Schottky diodes, the reflection coefficient is closely dependant on the $\mathrm{RF}$ input power. At $2.45 \mathrm{GHz}$, the reflection coefficient is lower than $-20 \mathrm{~dB}$ around $5 \mathrm{~mW}$, which is the incoming power per access that has been considered in the optimization process.

Figure 3 shows the simulated RF-to-DC conversion efficiency versus output load, for several input power levels, ranging from 0.1 to $10 \mathrm{~mW}$. Results clearly show that the maximum of efficiency is slightly dependant on the RF input level and is obtained for an output resistive load close to $1.2 \mathrm{k} \Omega$.

Due to the arbitrary angle of incidence of the RF signal incoming toward the dual patch rectenna, additional ADS simulations were performed to evaluate the influence of the phase difference between the two RF signals that feed the accesses of the rectifier. The amplitudes of both signals are considered to be equal. Fig. 4 illustrates the conversion efficiency against phase difference $(\Delta \Phi)$ for several total input power levels, ranging from 0.1 to $10 \mathrm{~mW}$. Results clearly show that the maximum efficiency is obtained in the balanced case when $\Delta \Phi=0^{\circ}$ and gradually decreases when $\Delta \Phi$ increases. 


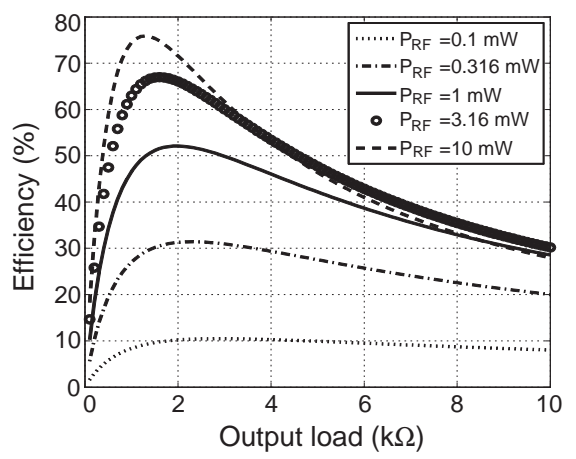

Figure 3. Conversion efficiency versus output load.

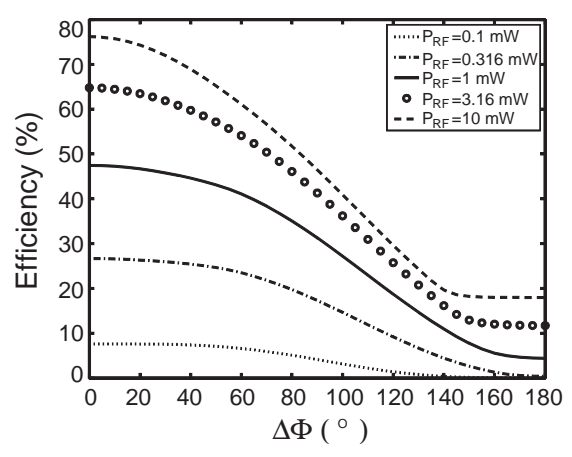

Figure 4. Conversion efficiency versus phase difference between the two accesses of the rectifier.

\section{RECTINNA CIRCUIT: 3D-FDTD MODELING}

The rectifier previously described has been associated with two linearly polarized patch antennas (see Fig. 5). The rectenna was etched on the Rogers Duroid 5880 substrate with $\varepsilon_{r}=2.2$ and $1.575 \mathrm{~mm}$ thickness.

The single patch antenna has been designed and optimized under Ansys HFSS software. Its dimensions are depicted on Fig. 5. The two patches have then been arranged to form the antenna array (see Fig. 6). The radiating elements are connected through a planar tee junction respectively constituted by a $50 \Omega$ and $25 \Omega$ characteristic impedance microstrip lines. The $50-\Omega$ feeding lines are $6.85 \mathrm{~mm}$ shifted at the edge of the antenna to excite the transverse vertical mode (along $x$ coordinate) of the antenna. This configuration is also called the $H$ -

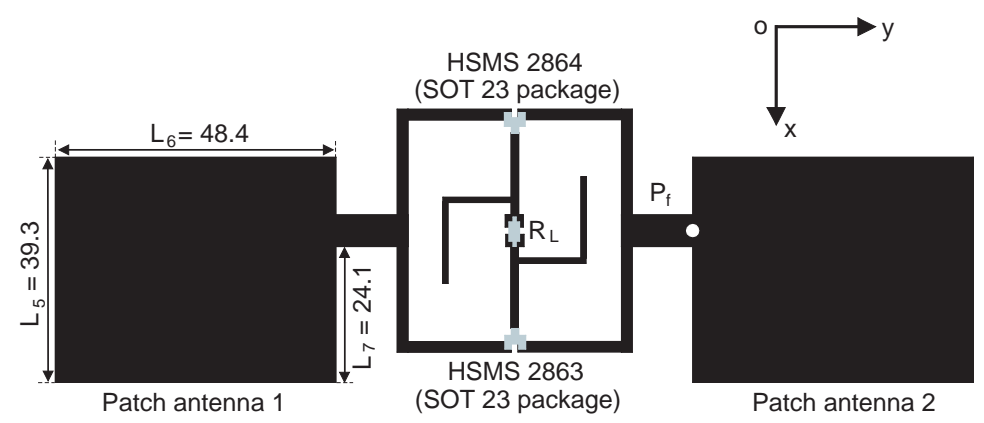

Figure 5. Layout of the proposed rectenna (All dimensions are in millimeters). 


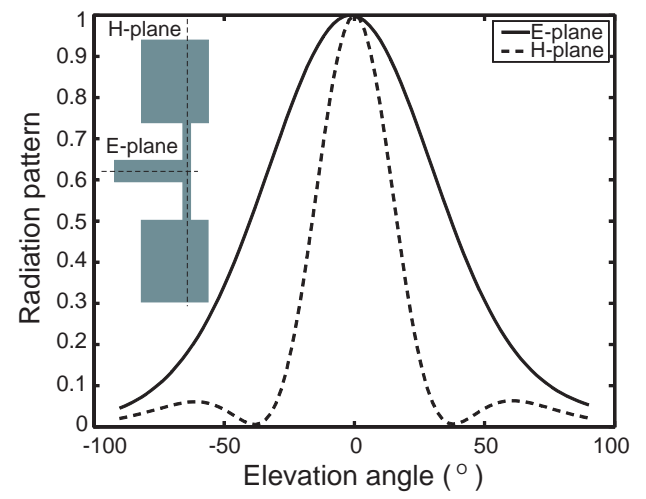

Figure 6. Normalized radiation pattern of the antenna array.

plane arrangement [21]. Here, the edge-to-edge separation is $56.9 \mathrm{~mm}$ $\left(\lambda_{0} / 2.15\right)$, resulting in a mutual coupling between patches less than $-32 \mathrm{~dB}$.

The array presents a simulated reflection coefficient $\left(S_{11}\right)$ of $-22 \mathrm{~dB}$. The simulated gain of the single patch antenna is $7.14 \mathrm{~dB}$ at $2.45 \mathrm{GHz}$ at its broadside $\left(\theta=0^{\circ}\right)$. This corresponds to an effective aperture of $61.8 \mathrm{~cm}^{2}\left(123.6 \mathrm{~cm}^{2}\right.$ for the corresponding dual patch array). The normalized radiation pattern of the antenna array in the $E$ - and $H$-planes is shown in Fig. 6. Two side lobes appear at $\theta \approx \pm 60^{\circ}$, in the $H$-plane.

To accurately analyze and take into account the electromagnetic couplings between the rectifying circuit and the patch antennas, the full-wave three-dimensional Finite Difference Time Domain 3D-FDTD method [22] has been introduced. The algorithm has been extended to lumped linear and non-linear elements [23-26] to describe and analyze the rectenna in term of current distributions [27]. Furthermore, the total-field/scattered-field formulation [28] and the Uniaxial Perfectly Matched Layers (UPML) [29] have also been used.

The FDTD parameters will be specified and simulation results presented and discussed. The smallest cells in the $x$ and $y$ directions are $\Delta x=0.467 \mathrm{~mm}$ and $\Delta y=0.279 \mathrm{~mm}$. Two cells have been chosen to correctly model the substrate thickness $(\Delta z=0.7875 \mathrm{~mm})$ along the $z$ axis. The total mesh dimensions are $227 \times 137 \times 49$ cells in the $x, y$ and $z$ directions, respectively. The time step is $0.726 \mathrm{ps}$ and simulations are performed considering 100000 time steps. The patch antennas are modeled by 41 cells in length $\left(L_{6}\right)$ and 56 cells in width $\left(L_{5}\right)$. The feed-line width $W_{1}$ and length $L_{1}$ are $15 \Delta x$ and $11 \Delta y$, respectively. Schottky diodes $\left(D_{1}\right.$ to $\left.D_{4}\right)$ are modeled by 
a $0.84 \mathrm{~mm} \times 0.82 \mathrm{~mm} \times 0.7875 \mathrm{~mm}$ cells and the output load $R_{L}$ is considered over two cells of $0.5 \mathrm{~mm}$ in length and one cell of $0.896 \mathrm{~mm}$ in width. Using the total-field/scattered-field formulation, the rectenna is illuminated by a linearly polarized incident plane wave of $E=19 \mathrm{~V} / \mathrm{m}$ $\left(\rho=96 \mu \mathrm{W} / \mathrm{cm}^{2}\right)$ at its broadside.

The rectifying circuit, described in Section 2, and the patch antenna are correctly matched. They present an input impedance close to $50 \Omega$ at $2.45 \mathrm{GHz}$. Due to the absence of the input HF filters, the influence of the antennas on the rectifier at 4.9 and $7.35 \mathrm{GHz}$ harmonic frequencies must be evaluated in term of input impedance. Table 2 shows the HFSS-simulated input impedance (real and imaginary parts) of the patch antenna at the $2.45 \mathrm{GHz}$ fundamental frequency and first harmonics, computed at the feed-point $P_{f}$ (see Fig. 5).

Table 2. Input impedance of the single patch antenna.

\begin{tabular}{|c|c|c|c|}
\hline Frequency & $\begin{array}{c}\text { Fundamental } \\
(2.45 \mathrm{GHz})\end{array}$ & $\begin{array}{c}\text { 2nd harmonic } \\
(4.9 \mathrm{GHz})\end{array}$ & $\begin{array}{c}\text { 3rd harmonic } \\
(7.35 \mathrm{GHz})\end{array}$ \\
\hline$R_{\text {in }}(\Omega)$ & 48.9 & 16 & 16 \\
\hline$X_{\text {in }}(\Omega)$ & 5.2 & -14 & 30.9 \\
\hline
\end{tabular}

The matching (or mismatching) stage is obtained by accurately adjust the length $L_{1}$ of the printed line between the antenna and the rectifier parts. Then, a parametric study has been conducted to find the optimal value of $L_{1}$ that provides an impedance matching at $2.45 \mathrm{GHz}$ and a mismatching at the second and third order harmonics.

Figure 7 shows the simulated output dc voltage and efficiency when $L_{1}$ varies from 6 up to $30 \mathrm{~mm}$. The FDTD results show that the efficiency decreases from $90.8 \%$ to $57.8 \%$ and the output dc voltage varies between 3.6 and $2.87 \mathrm{~V}$. For $L_{1}=8 \mathrm{~mm}$, an output dc voltage of $3.59 \mathrm{~V}$ and $90.6 \%$ efficiency were obtained. When $L_{1}$ decreases from $8 \mathrm{~mm}$ to $6 \mathrm{~mm}$, the rectenna output doesn't change greatly $\left(V_{\mathrm{DC}}=3.6 \mathrm{~V}\right.$ and $\left.\eta=90.8 \%\right)$. Therefore, this line length was set to be $8 \mathrm{~mm}$ for the experimental realization.

To accurately evaluate the influence of the line-length $L_{1}$ on the rectifier behavior at both second and third order harmonics, FDTD current distributions on transmission lines have been calculated for three different values of $L_{1}$ (14,20 and $26 \mathrm{~mm}$ ), after Fast Fourier Transform (FFT) computation. The current distributions $\left(J_{s}\right)$ are computed using tangential components of magnetic field $\left(H_{x}\right.$ and $\left.H_{y}\right)$. Results are depicted in Figs. 8 and 9.

When $L_{1}$ varies, the amount of power generated by the diodes at 4.9 and $7.35 \mathrm{GHz}$ could be transmitted to antennas where superficial 

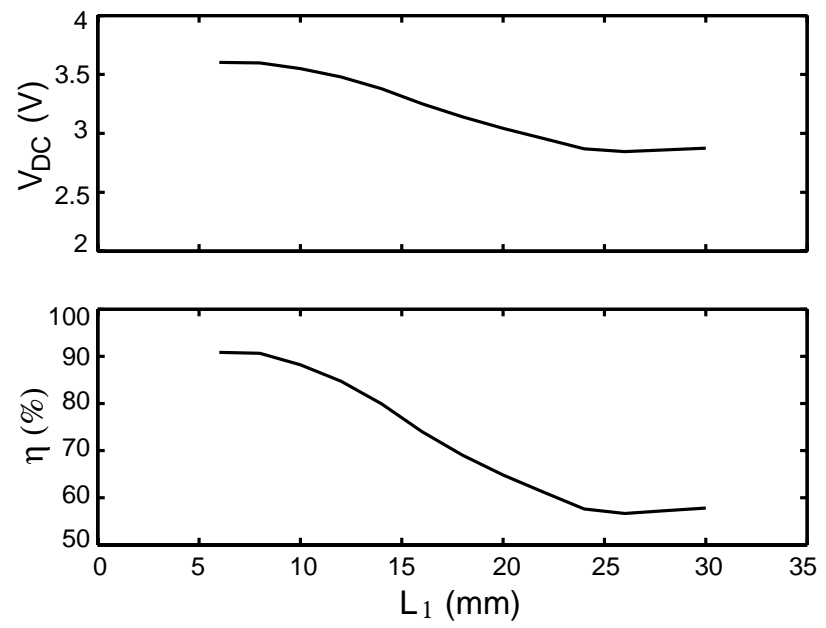

Figure 7. Rectenna dc output (voltage and efficiency) versus feed-line length $\left(L_{1}\right)$.

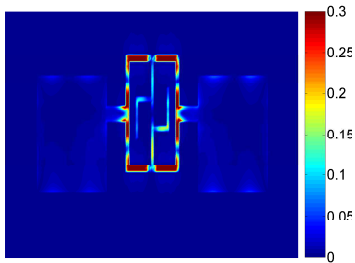

(a)

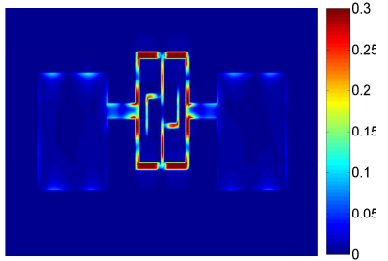

(b)

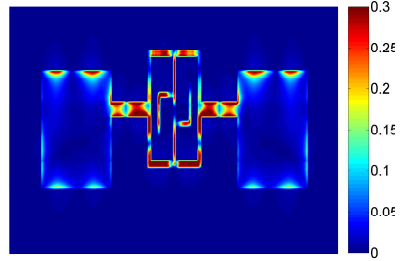

(c)

Figure 8. Current distributions at $4.9 \mathrm{GHz}$ for several values of $L_{1}$. (a) $L_{1}=14 \mathrm{~mm}$, (b) $L_{1}=20 \mathrm{~mm}$, (c) $L_{1}=26 \mathrm{~mm}$.

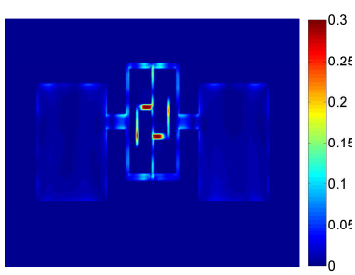

(a)

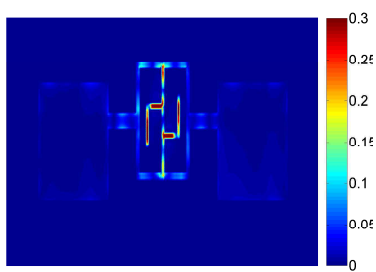

(b)

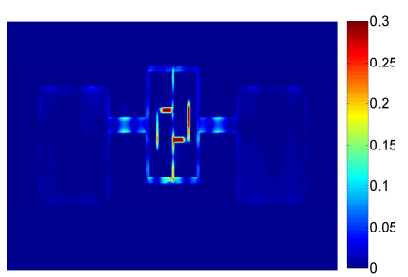

(c)

Figure 9. Current distributions at $7.35 \mathrm{GHz}$ for several values of $L_{1}$. (a) $L_{1}=14 \mathrm{~mm}$, (b) $L_{1}=20 \mathrm{~mm}$, (c) $L_{1}=26 \mathrm{~mm}$. 
current appears on the patches $\left(L_{1}=26 \mathrm{~mm}\right)$ and then radiated. There is no input lowpass filter and then, the patch antenna acts as a load for the rectifier at high order harmonics. This may modify the behavior of the rectifier and can decrease its performances.

Figure 10 shows the current distributions on transmission lines computed in the frequency domain when $L_{1}$ is optimal and set to be $8 \mathrm{~mm}$. This study will be limited to the $7.35 \mathrm{GHz}$ third order harmonic. Results show that all diodes $\left(D_{1}\right.$ to $\left.D_{4}\right)$ have the same dc current and that flowing through the output load $R_{L}$ is twice.

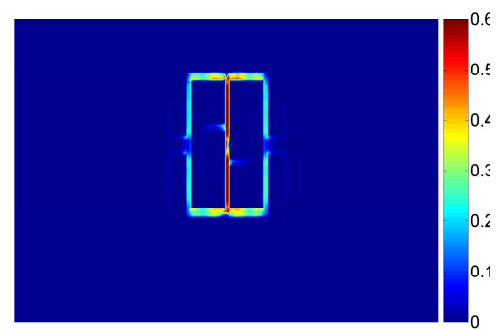

(a)

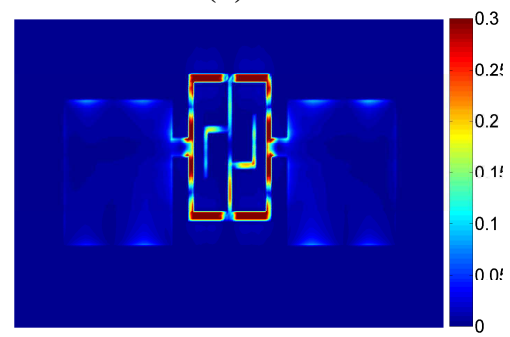

(c)

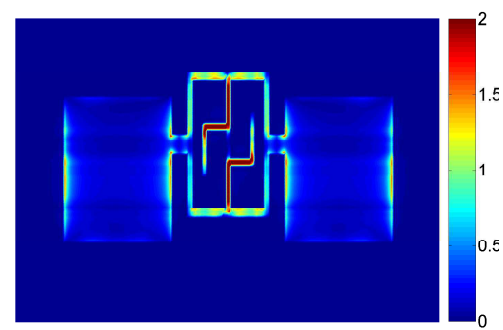

(b)

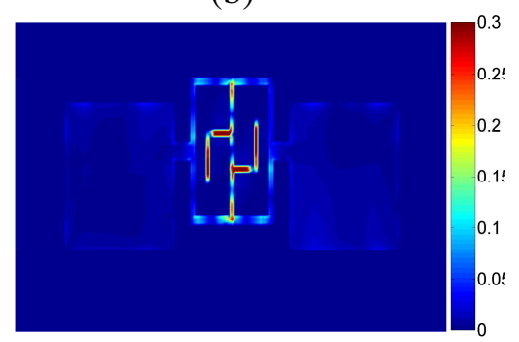

(d)

Figure 10. Current distributions $J_{s}(\mathrm{~A} / \mathrm{m})$. (a) DC, (b) $2.45 \mathrm{GHz}$, (c) $4.9 \mathrm{GHz}$, (d) $7.35 \mathrm{GHz}$.

At $2.45 \mathrm{GHz}$, two folded quarter wavelength open stubs, connected to points $P_{9}$ and $P_{10}$, behave like short circuits (a peak of current appears on the main lines). These stubs block the unwanted $2.45 \mathrm{GHz}$ fundamental frequency and isolate the resistive load $R_{L}$.

At the $4.9 \mathrm{GHz}$ second harmonic, the Schottky diodes have been accurately localized on a null of the current to minimize the power losses. In addition, the distance between $D_{1}\left(D_{3}\right)$ and $D_{2}\left(D_{4}\right)$ is three times half-wavelength at $4.9 \mathrm{GHz}$. Consequently, the second order harmonic is then distributed by a standing wave inside the main closed loop $P_{1}-P_{2}-P_{1}$ with a peak of current ( $\sim$ short circuit) at points $P_{1}$ and $P_{2}$. The unwanted second harmonic has been confined and there are no propagation effects towards microstrip patch antennas, 
where no current exists.

The results clearly show that the $7.35 \mathrm{GHz}$ third-order harmonic has a very low level and is reduced. It is mainly confined and distributed by a standing wave inside the rectifier part between points $P_{7}$ and $P_{8}$. By finely adjust the feed-line length $\left(L_{1}=8 \mathrm{~mm}\right)$, the antenna and the rectifier have been mismatched at this harmonic. The current distribution also shows that there are no propagation effects towards antennas, where no current appears.

\section{EXPERIMENTAL CHARACTERIZATION}

The rectenna shown in Fig. 5 has been realized and experimentally characterized inside an anechoic chamber using the dedicated measurement setup shown in Fig. 11. It contains an RF generator (Agilent E8251A) and a transmitting horn antenna $\left(G_{t}=12 \mathrm{~dB}\right)$. In addition, a power amplifier with $37 \mathrm{~dB}$ gain has been connected to the $\mathrm{RF}$ source to increase the transmitted power. The rectenna is localized in the far field zone $\left(\left(2 . D^{2} / \lambda_{0}\right)>53 \mathrm{~cm}\right)$ at a distance of $d=1 \mathrm{~m}$ from the transmitter. The output dc voltage across $R_{L}$ has been measured by a voltmeter.

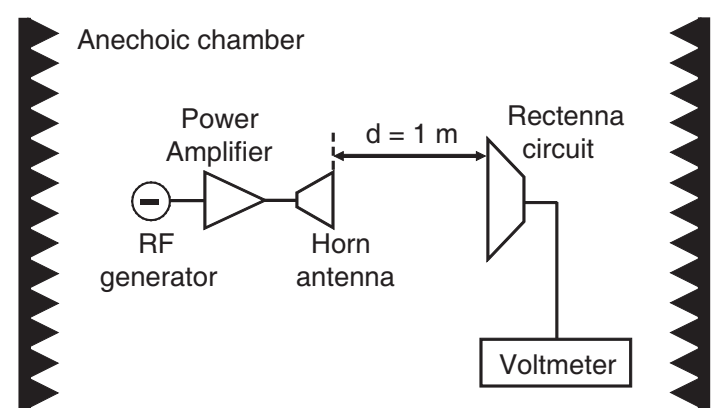

Figure 11. Dedicated measurement setup.

Two dedicated measurements have been performed. The first one consists to measure the dc voltage and efficiency as a function of power density and the second one consists to measure the output voltage as a function of elevation angle $(\theta)$ in both $E$ - and $H$-planes $\left(\Phi=0^{\circ}\right.$ and $\left.90^{\circ}\right)$.

The overall efficiency $(\eta)$ of the rectenna is defined as the ratio between the output dc power and the effective RF power. The Friis transmission equation including effective aperture of antennas and cable losses gives this effective incident $\mathrm{RF}$ power $\left(P_{\mathrm{RF}}\right)$ toward the rectifier [13]. 
The single patch antenna has been realized and experimentally characterized. It has a maximum gain of $6.2 \mathrm{~dB}$ and an effective aperture of $49.8 \mathrm{~cm}^{2}$. Thus, the total effective aperture of the dual patch array is set to be twice $\left(99.6 \mathrm{~cm}^{2}\right)$. The differences with the simulated results are mainly due to the tolerances during the fabrication process but also to the errors during the measurements.

The measured and FDTD simulated output dc voltages when received power density varies from 0 to $158 \mu \mathrm{W} / \mathrm{cm}^{2}(E=24.4 \mathrm{~V} / \mathrm{m}$, $P_{\mathrm{RF}}=15.7 \mathrm{~mW}$ ), are shown in Fig. 12(a). Experimental and FDTD curves are similar and are very close. The dc voltage increases when power density increases. For a low power density of $4.5 \mu \mathrm{W} / \mathrm{cm}^{2}$ $\left(E=4.1 \mathrm{~V} / \mathrm{m}, P_{\mathrm{RF}}=0.45 \mathrm{~mW}\right)$, an output voltage of $0.5 \mathrm{~V}$ was measured across an optimal load of $1.2 \mathrm{k} \Omega$. A maximum voltage of $4 \mathrm{~V}$ was measured when the power density is $158 \mu \mathrm{W} / \mathrm{cm}^{2}$. Fig. 12 (b) compares the measured and FDTD simulated rectenna efficiencies as a function of power density $\left(0-158 \mu \mathrm{W} / \mathrm{cm}^{2}\right)$.

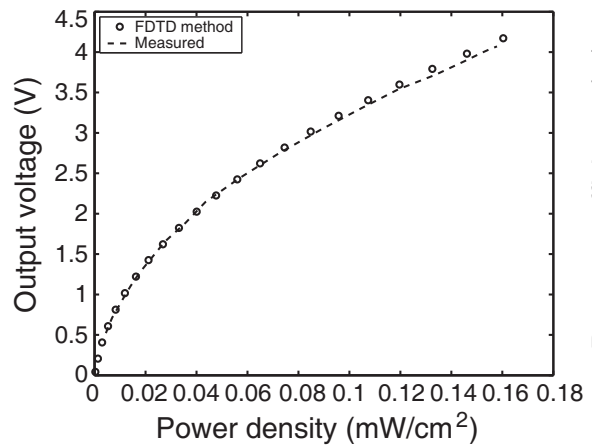

(a)

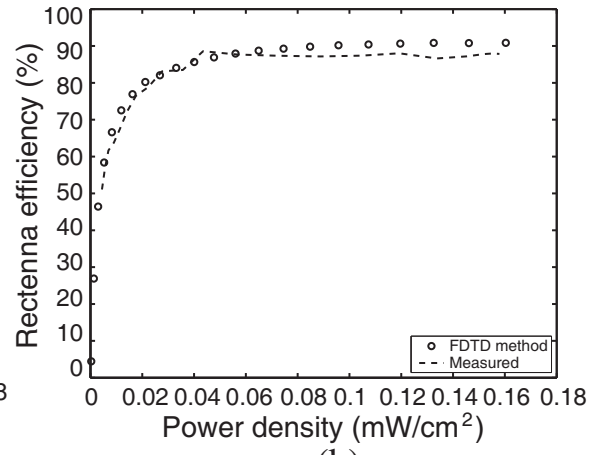

(b)

Figure 12. Simulated and measured (a) dc output voltage, (b) efficiency versus power density.

The experimental efficiency has a minimum value of $51.1 \%$ and is obtained at $4.5 \mu \mathrm{W} / \mathrm{cm}^{2}$. It exceeds $72 \%$ from $14 \mu \mathrm{W} / \mathrm{cm}^{2}(E=$ $\left.7.3 \mathrm{~V} / \mathrm{m}, P_{\mathrm{RF}}=1.4 \mathrm{~mW}\right)$ and is above $80 \%$ from $43 \mu \mathrm{W} / \mathrm{cm}^{2}(\mathrm{E}=$ $\left.12.8 \mathrm{~V} / \mathrm{m}, P_{\mathrm{RF}}=4.3 \mathrm{~mW}\right)$. Measurements are in good agreement with simulations. The differences between experiments and FDTD results are less than $3 \%$ in the power density range of $0-158 \mu \mathrm{W} / \mathrm{cm}^{2}$.

Figure 13 shows a comparison between measured and FDTD simulated output voltage as a function of elevation angle $(\theta)$ in both $E$ - and $H$-planes. To compare experimental and FDTD results, the rectenna was illuminated so that it receives the same RF power in both cases. In FDTD simulations, an incident plane wave of $96 \mu \mathrm{W} / \mathrm{cm}^{2}$ 
$\left(E=19 \mathrm{~V} / \mathrm{m}, P_{\mathrm{RF}}=11.9 \mathrm{~mW}\right)$ illuminates the rectenna. The maximum voltage was obtained at the broadside direction $\left(\theta=0^{\circ}\right)$ when patch antennas have a maximum gain and the $\mathrm{RF}$ signals toward the rectifier accesses are in phase. Outside this value, the output voltage decreases because the gain of the array decreases. Experimental results are in good agreement with FDTD method, both in $E$ - and $H$-planes. The output voltage exhibits, in the $E$-plane, a main lobe at $\theta=0^{\circ}$. However, in the $H$-plane, it presents a main lobe at $\theta=0^{\circ}$ and two side lobes at $\theta= \pm 54^{\circ}$. The shape of the voltage curves are closely similar to those of radiation pattern of the patch array presented in Fig. 6, where two side lobes appear at $\theta \approx \pm 60^{\circ}$.

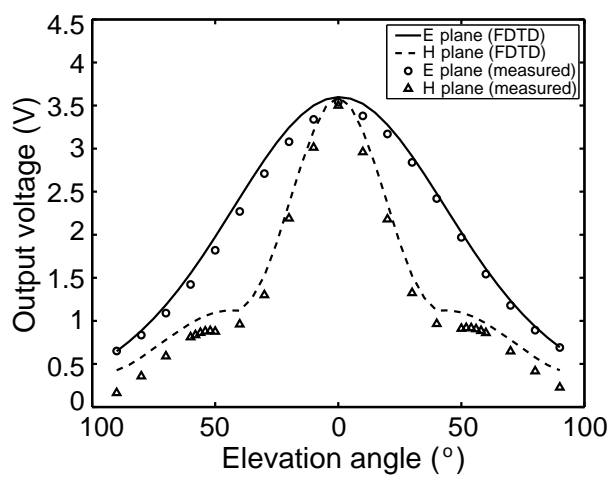

Figure 13. Simulated and measured output voltage against elevation angle in $E$ - and $H$-planes.

\section{CONCLUSION}

We have proposed in this paper the design and modeling of an efficient dual patch rectenna based on a full-wave rectifier at $2.45 \mathrm{GHz}$. Due to the symmetry of the rectifier and the optimized microstrip line sections, no input low-pass filter is needed. This greatly reduces the insertion losses, the dimensions of the circuit and improves the conversion efficiency. In addition, the differential measurement of the output dc voltage avoids the use of via-hole connections. In a first step, the rectifying circuit has been designed and optimized under ADS software for an input RF power of $10 \mathrm{~mW}$ ( $5 \mathrm{~mW}$ per access). In a second step, the proposed rectenna was simulated and analyzed using the full-wave 3D-FDTD method extended to lumped linear and non-linear elements. To accurately analyze the rectenna behavior, current distributions in the frequency domain have been computed and discussed. The proposed rectenna has been realized and experimentally 
characterized. It exhibits a measured efficiency of $73 \%$ at a power density of $14 \mu \mathrm{W} / \mathrm{cm}^{2}\left(E=7.3 \mathrm{~V} / \mathrm{m}, P_{\mathrm{RF}}=1.4 \mathrm{~mW}\right)$ and $84 \%$ at $43 \mu \mathrm{W} / \mathrm{cm}^{2}\left(E=12.8 \mathrm{~V} / \mathrm{m}, P_{\mathrm{RF}}=4.3 \mathrm{~mW}\right)$. An output dc voltage of $4 \mathrm{~V}$ has been measured through an optimal load of $1.2 \mathrm{k} \Omega$ when the power density is $158 \mu \mathrm{W} / \mathrm{cm}^{2}$. Measured results are very close to those obtained by the full-wave 3D-FDTD simulations. The differences on the efficiency are less than $3 \%$ over the power density range from 0 to $158 \mu \mathrm{W} / \mathrm{cm}^{2}$. The reported circuit can be useful for wireless power transmission applications. It should also find applications in ambient electromagnetic energy recycling, where power densities are relatively low. This new rectenna is particularly suitable to power remote supply of wireless and low consumption sensors, sensor nodes and actuators.

\section{ACKNOWLEDGMENT}

This work is supported by the ANR (Agence Nationale de la Recherche) through the project REC-EM ANR-10-BLAN-0906.

\section{REFERENCES}

1. Brown, W. C., "The history of power transmission by radio waves," IEEE Trans. Microw. Theory and Tech., Vol. 32, No. 9, 1230-1242, Sep. 1984.

2. Ren, Y. J. and K. Chang, "5.8-GHz circularly polarized dual-diode rectenna and rectenna array for microwave power transmission," IEEE Trans. Microw. Theory and Tech., Vol. 54, No. 4, 14951502, Apr. 2006.

3. Douyere, A., J. D. Lan, S. Luk, and F. Alicalapa, "High efficiency microwave rectenna circuit: Modeling and design," Electronics Letters, Vol. 44, No. 24, Nov. 2008.

4. Zbitou, J., M. Latrach, and S. Toutain, "Hybrid rectenna and monolithic integrated zero-bias microwave rectifier," IEEE Trans. Microw. Theory and Tech., Vol. 54, No. 1, 147-152, Jan. 2006.

5. Strassner, B. and K. Chang, "5.8- $\mathrm{GHz}$ circularly polarized rectifying antenna for wireless microwave power transmission," IEEE Trans. Microw. Theory and Tech., Vol. 50, No. 8, 18701876, Aug. 2002.

6. Heikkinen, J. and M. Kivikoski, "Low-profile circularly polarized rectifying antenna for wireless power transmission at $5.8 \mathrm{GHz}$," IEEE Microw. Wireless Compon. Lett., Vol. 14, No. 4, 162-164, Apr. 2004. 
7. Heikkinen, J. and M. Kivikoski, "A novel dual-frequency circularly polarized rectenna," IEEE Antennas Wireless Propag. Lett., Vol. 2, 330-333, 2003.

8. Akkermans, J. A. G., M. C. van Beurden, G. J. N. Doodeman, and H. J. Visser, "Analytical models for low-power rectenna design," IEEE Antennas Wireless Propag. Lett., Vol. 4, 187-190, 2005.

9. Takhedmit, H., B. Merabet, L. Cirio, B. Allard, F. Costa, C. Vollaire, and O. Picon, "Design of a $2.45 \mathrm{GHz}$ rectenna using a global analysis technique," Proceed. of the 3rd European Conference on Antennas and Propagation, EuCAP 2009, 23212325, Berlin, Germany, Mar. 23-27, 2009.

10. Marian, V., C. Vollaire, J. Verdier, and B. Allard, "An alternative energy source for low power autonomous sensors," Proceed. of the 5th European Conference on Antennas and Propagation, EuCAP 2011, 405-409, Rome, Italy, Apr. 11-15, 2011.

11. Ahn, C.-H., S.-W. Oh, and K. Chang, "A high gain rectifying antenna combined with reflectarray for $8 \mathrm{GHz}$ wireless power transmission," IEEE International Symposium on Antennas and Propagation, APSURSI 2009, 1-4, Charleston, USA, Jun. 1-5, 2009.

12. Olgun, U., C.-C. Chen, and J. L. Volakis, "Investigation of rectenna array configurations for enhanced RF power investigation," IEEE Antennas Wireless Propag. Lett., Vol. 10, 262-265, 2011.

13. Epp, L. W., A. R. Khan, H. K. Smith, and R. P. Smith, "A compact dual-polarized 8.51-GHz rectenna for high-voltage $(50 \mathrm{~V})$ actuator applications," IEEE Trans. Microw. Theory and Tech., Vol. 48, No. 1, 111-119, Jan. 2000.

14. Takhedmit, H., L. Cirio, B. Merabet, B. Allard, F. Costa, C. Vollaire, and O. Picon, "A 2.45-GHz dual-diode rectenna and rectenna arrays for wireless remote supply applications," Intern. Journ. of Microw. and Wireless Technolog., Vol. 3, Special issue 3, 251-258, Jun. 2011.

15. Monti, G., L. Corchia, and L. Tarricone, "ISM band rectenna using a ring loaded monopole," Progress In Electromagnetics Research C, Vol. 33, 1-15, 2012.

16. Monti, G. and F. Congedo, "UHF rectenna using a bowtie antenna," Progress In Electromagnetics Research C, Vol. 26, 181192, 2012.

17. Falkenstein, E., M. Roberg, and Z. Popovic, "Low-power wireless power delivery," IEEE Trans. Microw. Theory and Tech., Vol. 60, No. 7, 2277-2286, Jul. 2012. 
18. Farinholt, K. M., G. Park, and C. R. Farrar, "RF energy transmission for low-power wireless impedance sensor node," IEEE Sensors Journal, Vol. 9, No. 7, 793-800, Jul. 2009.

19. Advanced Design System software, Agilent Technologies, 20002013, Available: http://www.home.agilent.com/.

20. HSMS-286x, HSMS-282x series, Surface Mount Microwave Schottky Detector Diodes, 2001, Available: http://www.avagotech.com/.

21. Balanis, C. A., Antenna Theory: Analysis and Design, 3rd Edition, John Wiley \& Sons, Inc., 2005.

22. Taflove, A. and S. C. Hagness, "Computational electrodynamics — The finite difference time domain method," 3rd Edition, Artech House Inc., 2005.

23. Sui, W., D. A. Christensen, and C. H. Durney, "Extending the two dimensional FD-TD method to hybrid electromagnetic systems with active and passive lumped elements," IEEE Trans. Microw. Theory and Tech., Vol. 40, 724-730, 1992.

24. Toland, B., B. Houshmand, and T. Itoh, "FDTD analysis of an active antenna," IEEE Microwave and Guided Wave Letters, Vol. 3, No. 11, 423-425, Nov. 1993.

25. Kuo, C.-N., R.-B. Wu, B. Houshmand, and T. Itoh, "Modeling of microwave active devices using the fdtd analysis based on the voltage-source approach," IEEE Microwave and Guided Wave Letters, Vol. 6, No. 5, 199-201, May 1996.

26. Kuo, C.-N., B. Houshmand, and T. Itoh, "Full-wave analysis ok packaged microwave circuits with active and nonlinear devices: an FDTD approach," IEEE Trans. Microw. Theory and Tech., Vol. 45, No. 5, 819-826, May 1997.

27. Takhedmit, H., L. Cirio, B. Merabet, B. Allard, F. Costa, C. Vollaire, and O. Picon, "Efficient $2.45 \mathrm{GHz}$ rectenna design including harmonic rejecting rectifier device," Electronics Letters, Vol. 46, No. 12, 811-812, Jun. 10th, 2010.

28. Umashankar, K. and A. Taflove, "A novel method to analyze electromagnetic scattering of complex objects," IEEE Trans. on Electromagnetic Compatibility, Vol. 24, No. 4, 397-405, Nov. 1982.

29. Gedney, S. D., "An anisotropic perfectly matched layer-absorbing medium for the truncation of FDTD lattices," IEEE Trans. Antennas and Propagation, Vol. 44, No. 12, 1630-1639, Dec. 1996. 